\title{
Genetic expression of Col-2A and Col-10A as a function of administration of IGF-1 \& TGF- $\beta$ with and without anterior mandibular repositioning appliance on the growth of mandibular condylar cartilage in young rabbit
}

\author{
A. S. Patil ${ }^{1}$, R. B. Sable ${ }^{1}$, R. M. Kothari ${ }^{2}$, P. Nagarajan $^{2}$ \\ ${ }^{1}$ Deartment of Orthodontics and Dentofacial Orthopedics, Bharati Vidyapeeth Dental College and Hospital, Bharati Vidyapeeth \\ Deemed University, Pune, India \\ ${ }^{2}$ Rajiv Gandhi Institute of Biotechnology, Bharati Vidyapeeth Deemed University, Pune, India \\ Email: amolp66@yahoo.com
}

Received 25 September 2013; revised 31 October 2013; accepted 12 November 2013

Copyright (C) 2013 A. S. Patil et al. This is an open access article distributed under the Creative Commons Attribution License, which permits unrestricted use, distribution, and reproduction in any medium, provided the original work is properly cited.

\begin{abstract}
New Zealand (NZ) young rabbits with the administration of insulin-like growth factor (IGF-1) and transforming growth factor- $\beta$ (TGF- $\beta$ ) with and without mandibular anterior repositioning appliances are explored for the growth of the mandibular condylar cartilage (MCC). 32 growing NZ and rabbits were divided into 4 groups: the group with saline injection in TMJ, the group which received growth factor injection in TMJ, the group which received anterior positioning appliance and the group which received growth factors injection as well as mandibular repositioning appliance. Gene expression was studied by real-time RT-PCR and cartilage growth by histomorphometry. Administration of growth factors along with mandibular repositioning appliances has induced 1) 1.70 -fold expression of Col-2A gene ( $p$ value $<0.0005$ ) and 2 ) 1.47-fold expression of Col-10A gene ( $p$ value < 0.0005 ). In contrast, administration of only mandibular repositioning appliances induced 1) 1.28 -fold expression of Col-2A gene ( $p$ value $<0.0005$ ) and 2) merely 0.62 -fold expression of Col-10A gene ( $p$ value $<\mathbf{0 . 0 0 0 5}$ ), while administration of growth factors only induced 1) mere 0.56-fold expression of Col-2A gene (p value $<0.0005$ ) and 2$) 0.86$-fold expression of Col$10 \mathrm{~A}$ gene ( $p$ value $<0.0005)$. Administration of growth factors along with mandibular repositioning appliances causes an increase in genetic expressions which have been corroborated by histomorphometry and validated by statistical analysis, during an accelerated growth of mandibular condylar cartilage. Administration of growth factors in the TMJ could provide a
\end{abstract}

synergistic role along with mandibular repositioning appliances for treatment of mandibular retrognathism as well as disorders on the MCC.

Keywords: Transforming Growth Factor- $\beta$ (TGF- $\beta$ ); Insulin-Like Growth Factor (IGF-1); Condylar Cartilage Growth; Mandibular Repositioning Appliances; Col-2A; Col-10A

\section{INTRODUCTION}

This MCC plays a significant role in the development of oro-facial complex and has therefore received greater attention in orthodontics [1]. During its development, besides growth factors, condylar growth modification is induced by mandibular advancement as reported by Petrovic and Stutzmann [2]. Most of the studies in this regard have used either histological, histomorphometric, immuno-histomorphometric, biochemical or auto-radiographic methods as a diagnostic tool to evaluate the growth at the condyle [3-6] or detect increased expression of some growth factors/bio-markers of MCC growth [7-9]. Although, these studies have provided some valuable leads at a cellular level, several questions have remained unanswered. These could be answered only on a genetic level, elucidated by cellular studies for site specificity, quantified by molecular markers through biochemical analysis and their significance. The expression of Col-2A gene and its derivative protein (collagen II) is almost $80 \%$ component of the ECM in mice and rats whereas Type $\mathrm{X}$ collagen is localised in the hypertrophic and erosive zones of the condylar cartilage, where osteogenic transition takes place to facilitate endochondral 
ossification. Thus Col-2A and Col-10A play an important role in chondrogenesis of the mandibular condylar cartilage. TGF- $\beta$ and IGF-1 also have shown to have a synergistic effect on chondrogenesis and cartilage healing. Thus, the present study has precisely attempted such an integrated strategy for evaluation of condylar growth in young rabbits as a function of administration of growth factors (TGF- $\beta$ and IGF-1) with and without mandibular anterior repositioning appliances.

\section{MATERIALS AND METHODS}

\subsection{Experimental Subjects}

In this study, 60-day-old (pubertal age group) 32 male/ female NZ white rabbits were procured (Raj Biotechnology Laboratories, Pune), their use was approved by the Animal Ethical Committee of the Medical College of Bharati Vidyapeeth Deemed University (CPCSEA-012009) and experiments performed according to the guidelines laid down by the Committee for the Purpose of Control and Supervision of Experiments on Animals (CPCSEA) at the animal house of Bharati Vidyapeeth Medical College, Pune.

\subsection{Experimental Conditions}

The rabbits were maintained 1) in the animal house with fluoroscent light (12 hours day/12 hours night), relative humidity $95 \%$ and $\left.25^{\circ} \mathrm{C} \pm 1{ }^{\circ} \mathrm{C}, 2\right)$ provided with normal feed pellets (Amrut Seeds, Sangli), fresh green leafy vegetables and mineral water ad libitum and 3) their body weight and net weight of dry feed (pellets)/wet feed (cabbage/cauliflower/carrots) consumed determined daily.

\subsection{Experimental Design}

The rabbits were randomly divided into following four groups of 8 each (4 males and 4 females).

Group I-Saline injection in TMJ;

Group II-Growth factor injection in TMJ;

Group III-Mandibular advancement appliance with saline injection in TMJ;

Group IV-Mandibular advancement appliance with growth factor injection in TMJ.

\subsection{Appliance Fabrication}

Custom trays were prepared for taking impression of the upper incisors of rabbits using alginate, considering the anatomy oftheir upper arch studied on a rabbit head procured from a local abattoir (pre-experimental study) and appliances accordingly fabricated using heat-cure acrylic material [9] (IvoclarVivadent-SR TriplexHot) as shown in Figure 1.

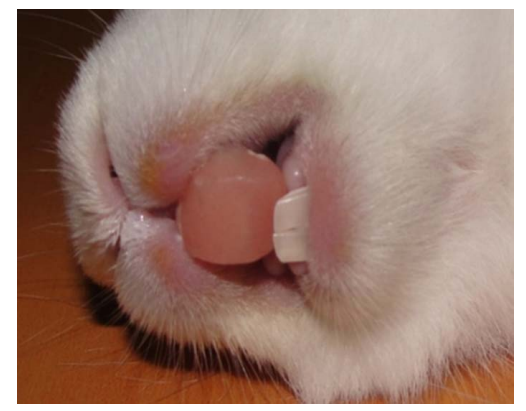

Figure 1. Mandibular repositioning appliance cemented on upper anteriors.

\subsection{Appliance Cementation}

Initially, appliances were tried on to the rabbits to examine irritation (if any), subsequently fitted at the proposed position by application of the adhesive material into the incisor slot and their cementation was done using Parapost dual-cure cement and light-cure unit to cure the cement. These were closely observed daily at 0600, 0930, $1230,1400,1630,2130$ and 2400 hours for retention of the appliance, its wear or damage, tissue irritation, somatic growth status (if any) and their tolerance, as judged from the quantum of food intake and body weight.

\subsection{Injection of Growth Factors}

Insulin-like Growth Factor-I (IGF-1, lyophilized powder from mouse recombinant expressed in Escherichia coli; Sigma) $25 \mathrm{ng} / 25 \mu \mathrm{l}$ and Transforming Growth Factor- $\beta-1$ (TGF- $\beta$, lyophilized powder from human platelets, $1 \times$ $10^{6}$ units $/ \mathrm{mg}$; Sigma) $20 \mathrm{ng} / 25 \mu \mathrm{l}$ were injected in the inferior joint space, by prior sedation of the rabbits with a combination of Xylaxine ( $5 \mathrm{mg} / \mathrm{kg}$ body wt.) and Ketamine $(35 \mathrm{mg} / \mathrm{kg}$ body wt.). The needle was directed at $45^{\circ}$ in reference to the mid-sagittal plane in the fossa behind the posterior orbital ridge, till it contacted the condyle. If the needle was not in precise location as judged by digital radiographs, desired correction in its angle and depth was ensured prior to injection of both the growth factors. The same procedure was repeated on the contra-lateral side too. The control group was injected with an equal volume of phosphate buffered saline (PBS) instead of growth factors, following the same procedure. The injections were administered on day 7 , day 14 and day 21 . Throughout the experimental duration, the rabbits were maintained at $25^{\circ} \mathrm{C}$ on feed prescribed before and euthanatized on day 30 , condyles recovered immediately, snap frozen in liquid nitrogen and stored at $-80^{\circ} \mathrm{C}$ until isolation of RNA.

\subsection{Real Time RT-PCR Technique}

The condylar tissue isolated from the 4 groups were 
treated with Ribopure kit (Ambion, USA), for rapid purification of total high quality RNA as per its protocol and stored at $-20^{\circ} \mathrm{C}$. Subsequently, RNA from each control and experimental sample was converted into c-DNA, using equal quantity of $2 \mathrm{X}$ RT master-mix in PCR tubes and thermo-cycled according to the protocol by c-DNA reverse transcription kit (Applied Biosystems, USA). The reaction was set in 48 well plates in an Applied Biosystems Step One Real Time PCR machine with the TaqMan technique., with each well containing $10 \mu \mathrm{l}$ Master mix TaqMan2X, $1 \mu \mathrm{l}$ primer (gene specific), $2 \mu \mathrm{l}$ c-DNA (sample specific), $7 \mu$ sterile $\mathrm{H}_{2} \mathrm{O}$, making total $20 \mu \mathrm{l}$ reaction mixture, and Glyceraldehyde-3-phosphate dehydrogenase (GAPDH) as the endogenous control. The primers used for the corresponding genes are shown in Table 1.

\subsection{Histomorphometry}

Alician Blue-PAS staining and Hematoxylin and Eosin staining was carried out for histologic sections and the slides were observed under Leica DM 5000B microscope under $10 \times$ magnification. The images were captured with a Leica DFC 320 camera and were analyzed by Leica Application Suite 3.70 Image analysis software.

\subsection{Statistical Analysis}

The data was statistically analyzed using Statistical Package for Social Sciences (SPSSver 11.5, Inc. Chicago, USA). The p-values less than 0.05 are considered to be statistically significant. All the hypotheses were formulated using two tailed alternatives against each null hypothesis (hypothesis of no difference). All results are presented as mean \pm standard deviation (SD) across the study groups and statistical significance of difference for histology tested using Mann-Whiteny U test, for testing the significance of difference between the independent groups with a relatively smaller sample size.

\section{RESULTS}

\subsection{Collagen-II Gene}

From Figure 2, Col-2A gene expression was 1) merely 0.56 -fold ( $\mathrm{p}$ value $<0.0005$ ) as a function of the administration of IGF-1 and TGF- $\beta, 2) 1.28$-fold increased ( $p$ value $<0.0005$ ) as a function of mandibular anterior repositioning appliance, indicating that the application of

Table 1. Profile of primer sequence used for the corresponding genes for TaqMan technique in real time RT-PCR.

\begin{tabular}{cc}
\hline Gene & Primer sequence \\
\hline Col-2A & CCTGGGCCTCAGGGACCTGCAGGTG \\
Col-10A & CGGGACTGCAAGGAGAGCCAGGGTT \\
\hline
\end{tabular}

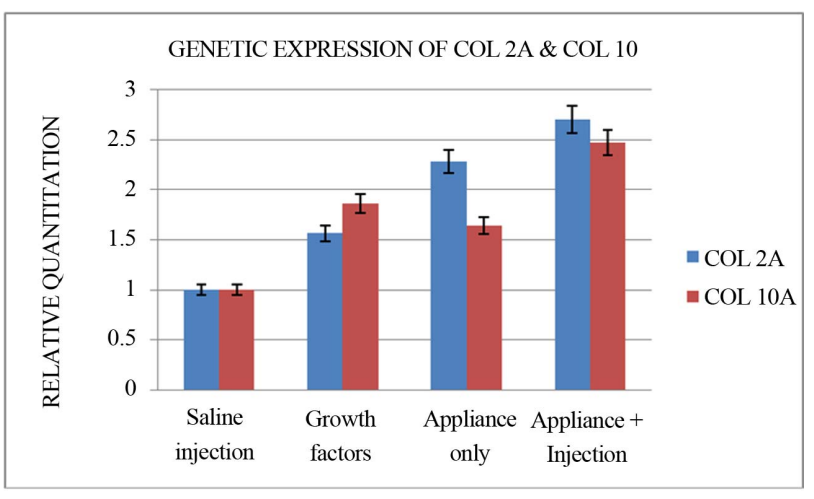

Figure 2. Histogram representing relative quantitation (RQ) of COL-2A and COL-10A gene.

appliances has induced positive effect, 3) 1.70-fold increased ( $p$ value $<0.0005$ ) as a function of mandibular repositioning group in conjunction with an administration of both the growth factors, pointing that this combined treatment has synergy and 4) in the order of AI > AS > I. Histo-chemical evidence (Figure 3) confirmed an enhanced PG biosynthesis as a molecular marker enmeshed in collagen-II protein which validates the expression of Col-2A gene during the condylar growth in the young rabbits.

\subsection{Collagen $X$ Gene}

From Figure 2, it is obvious that Col 10A gene expression was 1 ) 0.82 -fold ( $\mathrm{p}$ value $<0.0005$ ) as a function of the administration of IGF-1 and TGF- $\beta$, 2) mere 0.62 -fold ( $p$ value $<0.0005$ ) as a function of the mandibular anterior repositioning appliance, indicating that the application of appliances has indeed induced a negative effect, 3) 1.47-fold increased ( $p$ value $<0.0005$ ) as a function of the mandibular repositioning in conjunction with an administration of both the growth factors, pointing that this combined treatment has good degree of synergy and 4) the order of amplification is AI $>$ I $>$ AS.

\subsection{Histomorphometry}

The histo-chemical profile derived by staining with Alician Blue-PAS and Hematoxylin \& Eosin (H \& E) (Figure 3) showed 1) an increase in the size of the proliferative layer of the cartilage, 2) increase in the length of the cartilage. The histomorphometric measurements have been summarized in Table 2 and the statistical comparisons of the field mesurments are summarized in Table 3. The length of the condylar cartilage from the fibrous layer to the hypertrophic layer was greater in the group treated by appliances and growth factor as compared to the other groups (Figure 3).This is supported by an increase of the width in the cartilage in the descending order AI $>$ AS $>$ I $>$ S. Compared to the control, the in- 


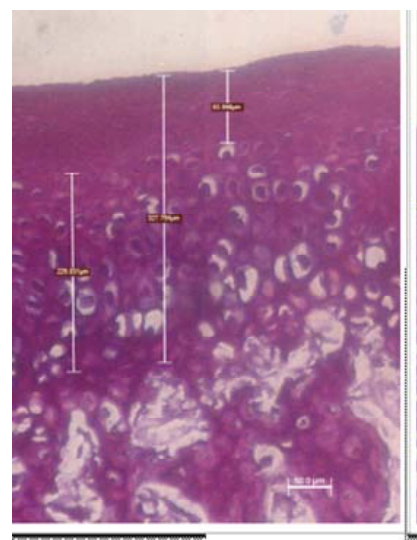

(a)

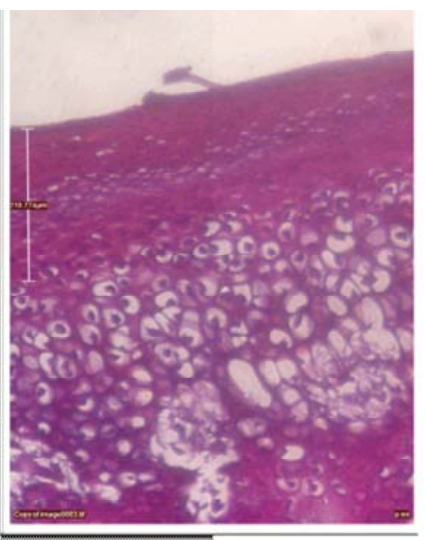

(b)

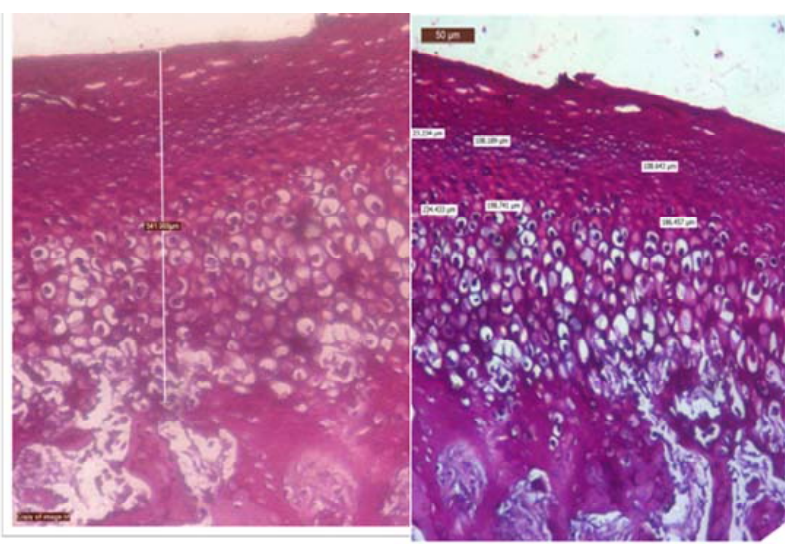

(c) (d)

Figure 3. Increase in the proliferative layer as compared to the hypertrophic layer and a concomitant increase in thickness in the cartilage in experimental groups. (a) Control group treated with injection of saline; (b) Experimental group treated with growth factor injection; (c) Group treated with mandibular advancement appliance; (d) Group treated with growth factor injection and mandibular advancement appliance.

Table 2. Comparison of histologic field measurements of MCC across the study groups.

\begin{tabular}{|c|c|c|c|c|}
\hline & $\begin{array}{l}\text { Group I } \\
\text { Saline } \\
\text { controls }\end{array}$ & $\begin{array}{l}\text { Group II } \\
\text { growth } \\
\text { factors }\end{array}$ & $\begin{array}{l}\text { Group III } \\
\text { Mandibular } \\
\text { appliance }\end{array}$ & $\begin{array}{l}\text { Group IIV } \\
\text { Mandibular } \\
\text { appliance }+ \\
\text { growth factors }\end{array}$ \\
\hline $\begin{array}{l}\text { Fibrous }+ \\
\text { proliferative zone }\end{array}$ & $54.7 \pm 19.1$ & $154 \pm 10.2$ & $160.7 \pm 15.7$ & $270 \pm 37.9$ \\
\hline $\begin{array}{l}\text { Hypertrophic }+ \\
\text { maturational } \\
\text { zone }\end{array}$ & $146.3 \pm 49.3$ & $98 \pm 20$ & $89.4 \pm 27.4$ & $89.5 \pm 30.9$ \\
\hline $\begin{array}{l}\text { Length of } \\
\text { cartilage }\end{array}$ & $214.9 \pm 61.7$ & $254 \pm 24$ & $262 \pm 24.2$ & $359.6 \pm 58.4$ \\
\hline
\end{tabular}

Table 3. Statistical comparison of histo-morphometric measurements of MCC (Students t test).

\begin{tabular}{cccc}
\hline & $\begin{array}{c}\text { Group I v/s } \\
\text { Group II }\end{array}$ & $\begin{array}{c}\text { Group I v/s } \\
\text { Group III }\end{array}$ & $\begin{array}{c}\text { Group I v/s } \\
\text { Group IV }\end{array}$ \\
\hline $\begin{array}{c}\text { Fibrous }+ \\
\text { proliferative zone } \\
\text { Hypertrophic }+ \\
\text { maturational zone } \\
\text { Length of cartilage }\end{array}$ & 0.001 & 0.001 & 0.001 \\
\hline
\end{tabular}

crease was significant in the experimental groups corroborating the RQ profile in Figure 1.

\section{DISCUSSION}

\subsection{Rationale Underlying the Choice of Rabbit as Experimental Aminal}

The choice of NZ rabbits as a dependable research model in the present study was made by virtue of their 1) placement as higher mammals than rodents and closer to human beings in the evolutionary scale for extrapolating observations made to clinical applicability, 2) temporomandibular joints (TMJ) being essentially identical to those in human beings, 3) jaw apparatus being specialized for herbivorous diet as in human beings and 4) administration of the growth factors in the TMJ/retro-discal tissue appeared to be precise because of larger TMJ compared to that of mice on which majority of the studies have been conducted so far (9).

\subsection{Real Time RT-PCR}

Since impaired growth of the condyles contributes to the development of mandibular asymmetries and retrognatia [10], role of mandibular condyles in the development of oro-facial complex has received focused attention of orthodontics. Accordingly, earlier studies on growing mice have thrown light on the post-natal cranio-facial skeletal growth and development in its entirety by delineating biochemical processes, certainly regulated by a complex network of genes and interacting genetic/epigenetic factors [11-13], which induce secretion of enzymes, growth factors, their receptors etc. representing integration of various physiological sub-processes [14]. As cartilage provides endochondral bone as an adaptive growth site during the mandibular development [10,15-17], present study has attempted to understand the expression of genetic factors (SOX-9, Col-2A and Col-10A) in young NZ rabbit model as a function of mandibular anterior repositioning appliances with and without the administration of TGF- $\beta$ and IGF-1 growth factors.

For this purpose, an accurate, sensitive and rapid measurement of the expression of these genes regulating the MCC growth using real time reverse transcription PCR (RT-PCR). 


\subsection{Expression of Collagen Specific Gene}

Gene expression for collagen II and collagen X whichhave contributed to ECM genesis in rat and mouse is studied for young rabbits also.

\subsubsection{Collagen II Gene}

Since matrix formation is a prerequisite during the growth and development of MCC, it was considered worthwhile to study the expression of Col-2A gene, its derivative protein (collagen II) being almost $80 \%$ component of the ECM in mice and rats. Accordingly, expression of Col-2A gene is depicted in Figure 2.

\subsubsection{Collagen X Gene}

After studying the profile of Col-2A gene, which is primarily found throughout the $\mathrm{ECM}$ in mice and rats, it was considered worthwhile to study the profile of Col-10A genes, which has exhibited high reactivity in the hypertrophic chondrocytes in the mineralization zone. This profile is depicted in Figure 2.

From Figure 2, it is obvious that Col-10A gene expression was 1) 0.82 -fold ( $p$ value $<0.0005$ ) as a function of the administration of IGF-1 and TGF- $\beta, 2$ ) mere 0.62 -fold ( $\mathrm{p}$ value $<0.0005$ ) as a function of the mandibular anterior repositioning appliance, indicating that the application of appliances has indeed induced a negative effect, 3)1.47-fold increased ( $p$ value $<0.0005$ ) as a function of the mandibular repositioning in conjunction with an administration of both the growth factors, pointing that this combined treatment has good degree of synergy and 4) the order of amplification is AI > I > AS. In contrast, Rabie et al. [18] noted 5.4 fold increase in type $\mathrm{X}$ collagen and 3.19 fold increase in collagen-II as a result of forward mandibular positioning in young Sprague Dawley rats. However, in the young rabbits biochemical assay has confirmed an enhanced PG biosynthesis in contrast to collagen II and X synthesis as a molecular marker; coupled with the histo-chemical evidence, enhanced expression of PG validates the condylar growth.

\subsection{Collagen II and Collagen X}

\subsubsection{Types of Collagen}

Over 19 types of collagen are known, each with a distinct biological function [19]. Among these types, a major sub-class is those of fibrillar collagens, which form the ordered extracellular fibrils; they are type I, type II, type III, type V and type XI collagens. While young cartilage cells contain pro-type I as well as pro-type II collagen, mature molecules of type I collagen appear only in the mineralisation zone of ECM, close to the ossification front. The condylar cartilage, a precursor of the new bone in the developing mandible, has been reported to contain only types I, II and X collagens in rats [20]. Thus, it appeared that different collagen types exist in different tissues, in different forms, in different ratios and in different times of aging.

\subsubsection{Localization of Type II and Type X Collagen}

Perichondrium, and not the cartilage, reacts positively for Type III collagen; type II is primarily found throughout the extracellular matrix (ECM) as soon as the chondroprogenitor cells are formed and in the cartilage, where it is the most abundant protein, responsible for its tensile strength, while type I and type III collagens are found in most non-cartilagenous tissues. In contrast, type XI collagen was recognized as a minor fibrillar collagen in the cartilage that was similar to type II collagen [21] and co-distributed with it in the cartilage and bone. When entrapped within type II collagen lattice, aggrecan molecules provide compressive strength to the cartilage. Type II collagen is also present in several other tissues in the early embryonic development and detected in the core of the newly formed bone trabeculae within the primary spongiosa. Ordinarily, type II collagen constitutes the major ingredient deposited in the ECM in the fibrous form, which accounts for about $80 \%$ of the organic matrix of the cartilage.

Type X collagen and capillary endothelium are localised in the hypertrophic and erosive zones of the condylar cartilage, where osteogenic transition takes place to facilitate endochondral ossification [21]. Only the hypertrophic chondrocytes within the mineralisation zone demonstrate an intense reactivity for the type $\mathrm{X}$ collagen, whilemild reactivity of type VI collagen is encountered throughout the condylar process.

\subsection{Role of Collagen during Condylar}

Intense research activity has been reported on the development of the mandible in general and mandibular condyles in particular, dealing with the growth changes during the use of different orthopedic appliances on experimental animals [2,22-24]. The MCC in the young animals, unlike other cartilages, is made up of a thick layer of precursor cells, specialised cells (chondroblasts and chondrocytes) and mineralised ECM. Condylar growth is regulated by a host of growth regulatory factors, which are endogenously expressed in the condyles, like the transcription factor SOX-9 which is required for the differentiation of chondrocytes and for the expression of a series of cartilage-specific marker genes, including types II, X and XI collagens [25].

In the condyles, once the mesenchymal cells differenttiate into chondrocytes, they mature, form the cartilage and express type II collagen. The emerging mature chondrocytes, later undergo hypertrophy and secrete type $\mathrm{X}$ collagen, which constitutes the matrix for the hypertrophic cartilage as a marker destined for endochondral 
ossification of the mandibular condyles [26,27]. Type X collagen and capillary endothelium are expressed in the hypertrophic and erosive zones of the condylar cartilage where osteogenic transition takes place to facilitate endochondral ossification [28].

\subsection{Role of TGF- $\beta$ in the Synthesis of Type-II Collagen}

Immuno-reactivity of TGF- $\beta$ isoforms with collagen type-II points out to their close association, physiologically and metabolically, during the genesis of MCC. Accordingly, collagen synthesis by TGF- $\beta$ in rabbit model 1) appeared critically dependent on extra-cellular environment, the effect varying with the differentiated state of chondrocytes, 2) was dose-dependent on procollagenase gene expression (especially for the synthesis of type II collagen which augmented adhesion) and 3) seemed stimulatory in human beings for type II collagen in OA, where adhesion of chondrocytes to type IV collagen decreased $[29,30]$. In fact, IGF-1 and TGF- $\beta$ induce expression of integrins, whose level is estimated by cell adhesion, especially to collagen and fibronectin in the ECM. However, distinguishing from these factors, TGF- $\beta$ markedly increases the efficiency of chondrocytes for colony formation in soft agar in the presence of exudates. These chondrocytes produce large amount of type-II collagen, without induction of type I, indicating that even elongated chondrocytes can express their differentiated functions and their shape is not necessarily crucial for the synthesis of cartilage matrix [31].

\subsection{Effect of Forward Mandibular Positioning on Secretion of Collagen}

\subsubsection{Type II Collagen}

Stimuli induced by the mechanical tension (tensile stress) tend to increase type II collagen expression, during the growth of the cartilage [32]. Mechanical stress generated out of masticatory functions further increases the expression of genes for aggrecan, type-II collagen and osteopontin. Type II collagen is expressed intensively in the ECM of the hypertrophic layer and inside the chondrocytes of the glenoid fossa. Forward mandibular positioning leads to a significant increase in the expression of type II collagen in the anterior, middle, and posterior regions and shows the maximum level of expression attained at $38^{\text {th }}$ day of the natural growth, followed by a gradual reduction in the expression thereafter.

Bio-mechanical forces induced by the forward mandibular positioning solicit cellular and molecular changes that lead to up-regulation in the expression of type II collagen in the glenoid fossa. These molecular changes improve our understanding of the tissue responses to functional appliance therapy [32,33]. Adaptation of the condylar cartilage to the mandibular forward positioning has been considered to constitute the biologial basis for an altered osteogenic transition of chondrogenesis that leads to increased endochondral ossification [34].

\subsubsection{Type X Collagen}

Type X collagen expression precedes the onset of endochondral ossification in the mandibular condyles [27,35]. Type $\mathrm{X}$ collagen is synthesized exclusively by the hypertrophic chondrocytes and its expression indicates the termination of chondrogenesis [35]. A similarity in the temporal pattern, but a significant difference in the quantity of type $\mathrm{X}$ collagen synthesis between these two (natural vs adaptive) groups indicates that the rate of chondrocyte maturation under an adaptive remodelling is consistent with that under the natural growth, but at a more enhanced degree [32]. In the growing rats, type $X$ collagen expression was significantly $(541 \%)$ enhanced upon the mandibular advancement. The cells constituting this newly formed cartilaginous matrix in the growing condyle undergo hypertrophy and synthesize the hypertrophic matrixby type $X$ collagen [36,37].

Type $\mathrm{X}$ collagen being relevant to the mineralization of the cartilage, it is present in the hypertrophic cell layer in the growth stage. It is ubiquitously observed, even after the hypertrophic cell layer has disappeared, in the area immediately above the mineralizing front of the cartilage matrix. This finding suggests that type X collagen is not produced for the sole purpose of inducing hypertrophy in the chondrocytes. In this regard, Ekanayake and Hall [37] reported that both hypertrophic and small chondrocytes express type $\mathrm{X}$ collagen, when both types of chondrocytes undergo the process of mineralization in vitro. Immuno-histochemical localization of type $\mathrm{X}$ collagen in the MCC showed that it is secreted in the early stages of temporomandibular disorders, indicating the possibility of a change in the matrix during the mineralization process [38].

The proposed mechanism of type $X$ collagen 1) involves expression specifically in the hypertrophic cartilage, indicating its role in the terminal stage of the chondrocyte maturation, 2) regulates calcification during the endochondral ossification and 3) provides an easily resorbable fabric for the deposition of the bone matrix [39].

In the present study, young rabbits have shown preference to biosynthesis of PG in sharp contrast to biosynthesis of collagen Type-II observed in mice and rats. These figures of expression of Col2A and $\mathrm{Col} 10 \mathrm{~A}$ gene cumulatively emphasize relatively less significance of type II collagen and type X collagen over the synthesis of above-mentioned derivatives of PG in the formation of extracellular matrix (ECM) in the young rabbits. These observations are finally validated by a mere 0.70 - 
fold increase in the expression of collagen II gene and a mere 0.47 -fold increase in the expression of collagen $\mathrm{X}$ gene (Figure 2).

\section{CONCLUSIONS}

The following genes expressed after the administration of growth factors along with mandibular repositioning appliances has induced 1) 1.70-fold expression of Col$2 \mathrm{~A}$ gene ( $\mathrm{p}$ value $<0.0005), 2) 1.47$-fold expression of Col-10A gene ( $\mathrm{p}$ value $<0.0005$ ); whereas administration only of mandibular repositioning appliances has induced 1) 1.28-fold expression of Col-2A gene ( $\mathrm{p}$ value $<0.0005)$, 3) 0.62-fold expression of Col-10A gene ( $p$ value $<0.0005$ ) and administration of growth factors only has induced 1) 0.56-fold expression of Col-2A gene ( $p$ value $<0.0005$ ), 3) 0.86 -fold expression of Col-10A gene ( $\mathrm{p}$ value $<0.0005$ ).

In conclusion, this effort is superior to the in vivo studies in the scope and certainly educative in the observations derived from the in vitro studies. In the ultimate analysis, it may prove that reach of the genes is much longer than human beings have ever envisaged.

\section{ACKNOWLEDGEMENTS}

ASP acknowledges the assistance of Dr. Prashant Khadke, Dr. Uday Deshpande, Dr. Dada Akolkar and Mr. Mandar from LAB INDIARGITBT collaboration in the gene expression studies and Mrs. Soumya Koppikar in the analysis of PG.

\section{REFERENCES}

[1] Patil, A.S., Sable, R.B. and Kothari, R.M. (2011) An update on transforming growth factor- $\beta$ (TGF- $\beta$ ): Sources, types, functions and clinical applicability for cartilage/ bone healing. Journal of Cellular Physiology, 226, 30943103. http://dx.doi.org/10.1002/jcp.22698

[2] Petrovic, A.G. and Stutzmann, J.J. (1977) Further investigations into the functioning of the peripheral comparator of the servosystem in the control of the condylar cartilage growth rate and the lengthening of the jaw. In: McNamara, J.A., Ed., The Biology of Occlusal Development, Monograph 7, 255-291.

[3] Ghafari, J. and Degroote, C. (1986) Condylar cartilage response to continuous mandibular displacement in the rat. Angle Orthodontist, 56, 49-57.

[4] Patil, A.S., Merchant, Y. and Nagarajan, P. ( 2013) Tissue engineering of craniofacial tissues. Journal of Regenerative Medicine and Tissue Engineering, 2, 1-19.

[5] Blumenfeld, I., Gasper, R., Laufer, D. and Livne, E. (2000) Enhancement of toluidine blue staining by transforming growth factor, insulin like growth factors and growth hormone in the temporomandibular joint of aged mice. Cells Tissues Organs, 167, 121-129.

http://dx.doi.org/10.1159/000016775

[6] Proff, P., Gedrange, T., Franke, R., Schubert, H., Fang- hanel, J., Miehe, B., et al. (2007) Histological and histomorphometric investigation of the condylar cartilage of juvenile pigs after anterior mandibular displacement. Annals of Anatomy, 189, 269-275. http://dx.doi.org/10.1016/j.aanat.2006.09.006

[7] Patil, A.S., Sable, R.B. and Kothari, R.M. (2012) Role of insulin-like growth factors (IGFs), their receptors and genetic regulation in the chondrogenesis and growth of the mandibular condylar cartilage. Journal of Cellular Physiology, 227, 1796-1804. http://dx.doi.org/10.1002/jep.22905

[8] Doshi, R.R. and Patil, A.S. (2012) Genes in craniofacial growth. IIOAB Journal, 3, 19-36.

[9] Patil, A.S., Sable, R.B. and Kothari, R.M. (2012) Genetic expression of MMP-1 and MMP-13 as a function of anterior mandibular repositioning appliance on the growth of mandibular condylar cartilage with and without administration of IGF-1 and TGF-b. Angle Orthodontist, 82, 1053-1059. http://dx.doi.org/10.2319/122011-780.1

[10] Bushang, P.H. and Hinton, R.J. (2005) A gradient of potential of modifying craniofacial growth. Seminars in Orthodontics, 11, 219-226.

http://dx.doi.org/10.1053/j.sodo.2005.07.006

[11] Visnapuu, V., Peltomaki, T., Ronning, B., Vahlberg, T. and Helenius, H. (2001) Growth hormone and insulin-like growth factor receptors in the temporomandibular joint of the rat. Journal of Dental Research, 80, 1903-1907. http://dx.doi.org/10.1177/00220345010800100801

[12] Shen, G. and Darendeliler, M.A. (2005) The adaptive remodeling of condylar cartilage-A transition from chondrogenesis to osteogenesis. Journal of Dental Research, 84, 691-699. http://dx.doi.org/10.1177/154405910508400802

[13] Von Den Hoff, J.W. and Delatte, M. (2008) Interplay of mechanical loading and growth factors in the mandibular condyle. Archives of Oral Biology, 53, 709-715. http://dx.doi.org/10.1016/j.archoralbio.2008.03.002

[14] Patil, A.S., Sable, R.B. and Kothari, R.M. (2012) Occurrence, biochemical profile of vascular endothelial growth factor (VEGF) isoforms and their functions in endochondral ossification. Journal of Cellular Physiology, 227, 1298-1308. http://dx.doi.org/10.1002/jcp.22846

[15] Rabie, A.B. and Hägg, U. (2002) Factors regulating mandibular condylar growth. American Journal of Orthodontics and Dentofacial Orthopedics, 122, 401-409. http://dx.doi.org/10.1067/mod.2002.125713

[16] Carlson, D.S. (2002) Biological rationale for early treatment of dentofacial deformities. American Journal of Orthodontics and Dentofacial Orthopedics, 121, 554-558. http://dx.doi.org/10.1067/mod.2002.124164

[17] Rabie, A.B.M., Wong, L. and Tsai, M. (2003) Replicating mesenchymal cells in the condyle and the glenoid fossa during mandibular forward positioning. American Journal of Orthodontics and Dentofacial Orthopedics, 123, 49-57. http://dx.doi.org/10.1067/mod.2003.46

[18] Suzuki, S., Itoh, K. and Ohyama, K. (2004) Local administration of IGF-I stimulates the growth of mandibular condyle in mature rats. Journal of Orthodontics, 31, 138143. http://dx.doi.org/10.1179/146531204225020436 
[19] Prockop, D.J. (1995) Collagens: Molecular biology, diseases, and potentials for therapy. Annual Review of Biochemistry, 64, 403-434. http://dx.doi.org/10.1146/annurev.bi.64.070195.002155

[20] Luder, H.U., Leblond, C.P. and Von Der Mark, K. (1988) Cellular stages in cartilage formation as revealed by morphometry, radioautography and type II collagen immunostaining of the mandibular condyle. Weaning Rats, 182, 197-204.

[21] Shen, G., Zhao, Z., Kaluarachchi, K. and Rabie, A.B. (2006) Expression of type X collagen and capillary endothelium in condylar cartilage during transition from chondrogenesis to osteogenesis-A comparison between condylar adaptation and natural growth. European Journal of Orthodontics, 28, 210-216. http://dx.doi.org/10.1093/ejo/cji123

[22] Hinton, R.J. and Mc Namara Jr., J.A. (1984) Temporal bone adaptations in response to protrusive function in juvenile and young adult rhesus monkeys (Macacamulatta). European Journal of Orthodontics, 6, 155-174.

[23] Kantomaa, T. (1987) Reactions of the condylar tissues to attempts to increase mandibular growth. Scandinavian Journal of Dental Research, 95, 335-339.

[24] Johnston Jr., L.E. (1996) Functional appliances: A mortgage on mandibular position. Australian Orthodontic Journal, 14, 154-157.

[25] De Crombrugghe, B., Lefebvre, V. and Nakashima, K. (2001) Regulatory mechanisms in the pathways of cartilage and bone formation. Current Opinion in Cell Biology, 13, 721-727. http://dx.doi.org/10.1016/S0955-0674(00)00276-3

[26] Salo, L.A., Metsikko, K., Palokangas, H., Lehenkari, P. and Väänänen, H.K. (1996) The expression of types X and VI collagen and fibrillin in rat mandibular condylar cartilage. Response to mastication forces. Acta Odontologica Scandinavica, 5, 295-302. http://dx.doi.org/10.3109/00016359609003541

[27] Rabie, A.B.M., Shen, G., Hägg, U. and Kalurachchi, T. (2000) Type X collagen-A marker for endochondral ossification of the mandibular condyles. Quintessence Orthodont Year Book, 50-58.

[28] Shen, G., Zhao, Z., Kaluarachchi, K. and Rabie, A.B. (2006) Expression of type X collagen and capillary endothelium in condylar cartilage during transition from chondrogenesis to osteogenesis - A comparison between condylar adaptation and natural growth. European Journal of Orthodontics, 28, 210-216. http://dx.doi.org/10.1093/ejo/cji123

[29] Yaeger, P.C., Masi, T.L., De Ortiz, J.L., Binette, F., Tubo, R. and Mcpherson, J.M. (1997) Synergistic action of transforming growth factor-beta and insulin-like growth factor-I induces expression of type II collagen and aggrecan genes in adult human articular chondrocytes. Experimental Cell Research, 237, 318-325. http://dx.doi.org/10.1006/excr.1997.3781
[30] Grimaud, E., Heymann, D. and Redini, F. (2002) Recent advances in TGF- $\beta$ effect on chondrocyte metabolism: Potential therapeutic roles of TGF- $\beta$ in cartilage disorders. Cytokine \& Growth Factor Reviews, 13, 241-257. http://dx.doi.org/10.1016/S1359-6101(02)00004-7

[31] Inoue, H., Kato, Y., Ivamoto, M., Hiraki, Y., Sakuda, M. and Suzuki, F. (1989) Stimulation of cartilage-matrix proteoglycan synthesis by morphologically transformed chondrocytes grown in the presence of fibroblast growth factor and transforming growth factor-beta. Journal of Cellular Physiology, 138, 329-337. http://dx.doi.org/10.1002/jcp.1041380216

[32] Rabie, A.B.M., She, T.T. and Harley, V.R. (2003) Forward mandibular positioning up-regulates SOX9 and type II collagen expression in the glenoid fossa. Journal of Dental Research, 82, 725-730. http://dx.doi.org/10.1177/154405910308200913

[33] Kantomaa, T. and Pirttiniemi, P. (1998) Changes in proteoglycan and collagen content in the mandibular condylar cartilage of the rabbit caused by an altered relationship between the condyle and glenoid fossa. European Journal of Orthodontics, 20, 435-441. http://dx.doi.org/10.1093/ejo/20.4.435

[34] Rabie, A.B., Shum, L. and Chayanupatkul, A. (2002) VEGF and bone formation in the glenoid fossa during forward mandibular positioning. American Journal of Orthodontics and Dentofacial Orthopedics, 122, 202-209. http://dx.doi.org/10.1067/mod.2002.125991

[35] Nishida, N., Fukuda, Y., Komeda, T., Ito, T., Nishimura, T., Minata, M., Kuno, M., Katsuma, H., Ikai, I., Yamaoka, Y. and Nakao, K. (2002) CTGF/Hcs24, a hypertrophic chondrocyte specific gene product, stimulates proliferation and differentiation, but not hypertrophy of cultured articular condrocytes. Journal of Cellular Physiology, 192, 55-63. http://dx.doi.org/10.1002/jcp.10113

[36] Rabie, A.B. and Hägg, U. (2002) Factors regulating mandibular condylar growth. American Journal of Orthodontics and Dentofacial Orthopedics, 122, 401-409. http://dx.doi.org/10.1067/mod.2002.125713

[37] Ekanayake, S. and Hall, B.K. (1994) Hypertrophy is not a prerequisite for type $\mathrm{X}$ collagen expression or mineralizetion of chondrocytes derived from cultured chick mandibular ectomesenchyme. The International Journal of Developmental Biology, 38, 683-694.

[38] Ohashi, N., Robling, A.G., Burr, D.B. and Turner, C.H. (2002) The effects of dynamic axial loading on the rat growth plate. Journal of Bone and Mineral Research, 17, 284-292. http://dx.doi.org/10.1359/jbmr.2002.17.2.284

[39] Fukada, K., Shibata, S., Suzuki, S., Ohya, K. and Kuroda, T. (1999) In situ hybridisation study of type I, II, X collagens and aggrecan mRNAs in the developing condylar cartilage of fetal mouse mandible. Journal of Anatomy, 195, 321-329. http://dx.doi.org/10.1046/j.1469-7580.1999.19530321.x 